\title{
Is Aerosol Geoengineering Ethically Preferable to Other Climate Change Strategies?
}

Toby Svoboda

Fairfield University, tsvoboda@fairfield.edu

Follow this and additional works at: https://digitalcommons.fairfield.edu/philosophy-facultypubs Copyright 2012 Indiana University Press. A post-print has been archived here with permission from the copyright holder.

\section{Peer Reviewed}

\section{Repository Citation}

Svoboda, Toby, "Is Aerosol Geoengineering Ethically Preferable to Other Climate Change Strategies?" (2012). Philosophy Faculty Publications. 27.

https://digitalcommons.fairfield.edu/philosophy-facultypubs/27

\section{Published Citation}

Svoboda, Toby (2012). Is Aerosol Geoengineering Ethically Preferable to Other Climate Change Strategies? Ethics and the Environment Vol. 17 No. 2. pg 111-135.

This item has been accepted for inclusion in DigitalCommons@Fairfield by an authorized administrator of DigitalCommons@Fairfield. It is brought to you by DigitalCommons@Fairfield with permission from the rightsholder(s) and is protected by copyright and/or related rights. You are free to use this item in any way that is permitted by the copyright and related rights legislation that applies to your use. For other uses, you need to obtain permission from the rights-holder(s) directly, unless additional rights are indicated by a Creative Commons license in the record and/or on the work itself. For more information, please contact digitalcommons@fairfield.edu. 


\title{
Is Aerosol Geoengineering Ethically Preferable to Other Climate Change Strategies?
} (Post-Print Version)

\author{
Toby Svoboda (Assistant Professor of Philosophy, Fairfield University) \\ Published in Ethics \& the Environment 17:2 (2012): 111-135 ${ }^{1}$
}

\begin{abstract}
.
As a strategy for responding to climate change, aerosol geoengineering (AG) carries various risks, thus raising ethical concerns regarding its potential deployment. I examine three ethical arguments that AG ought not to be deployed, given that it (1) risks harming persons, (2) would harm persons, and (3) would be more harmful to persons than some other available strategy. I show that these arguments are not successful. Instead, I defend a fourth argument: in scenarios in which all available climate change strategies would result in net harm, we ought to adopt the strategy that would result in the least net harm. Barring substantial cuts in greenhouse gas emissions, we can reasonably expect future scenarios in which all available strategies would result in net harm. In such cases, there is good reason to suspect that AG would result in less net harm than emissions mitigation, adaptation, or other geoengineering strategies.
\end{abstract}

\section{Introduction.}

In this paper, I address the question of whether aerosol geoengineering (AG) ought to be deployed as a response to climate change. First, I distinguish AG from emissions mitigation, adaptation, and other geoengineering strategies. Second, I discuss advantages and disadvantages of AG, including its potential to result in substantial harm to some persons. Third, I critique three

\footnotetext{
${ }^{1}$ This article was published as "Is Aerosol Geoengineering Ethically Preferable to Other Climate Change Strategies?” Ethics \& the Environment 17:2 (2012): 111-135. No part of this article may be reproduced, stored in a retrieval system, transmitted, or distributed, in any form, by any means, electronic, mechanical, photographic, or otherwise, without the prior permission of Indiana University Press.
} 
arguments against AG deployment, suggesting reasons why these arguments should be rejected. Fourth, I consider an argument that, in scenarios in which all available climate change strategies would result in net harm to persons, we ought to adopt that response to climate change which would result in the least net harm. I suggest that under certain conditions, such as a climate emergency scenario, the least harmful climate change strategy plausibly could involve deployment of AG. The implication is that, despite the risks of harm associated with it, in certain situations AG could be (or be part of) a climate change strategy that is ethically preferable to other available strategies.

\section{Mitigation, Adaptation, Geoengineering.}

Climate change could result in severe harm for some persons ${ }^{1}$ through various impacts, including sea-level rise, ocean acidification, droughts, and an increase in the frequency of severe weather events (IPCC 2007b). Partly because anthropogenic emissions of greenhouse gases are the driving forces behind these potentially harmful impacts, climate change raises a number of ethical issue (Singer 2004, 14-50; Gardiner 2004). But what ought to be done to reduce or, if feasible, eliminate the harm that climate change threatens to cause? Frequently discussed options include mitigating greenhouse gas emissions (Nordhaus 2001) and adapting to the impacts of climate change (Lobell et al. 2008). A more radical option is geoengineering, or the intentional, large-scale manipulation of the Earth’s environment (Keith 2001). In recent years, a growing number of scientists has called for more research on geoengineering as a potential response to climate change (Crutzen 2006; Shepherd 2009; MacCracken 2006; Keith, Parson, and Morgan 2010). 
Geoengineering techniques can be divided into two categories. First, carbon dioxide $\left(\mathrm{CO}_{2}\right)$ removal would reduce the quantity of greenhouse gases in the atmosphere, either by trapping emissions at their sources or by drawing $\mathrm{CO}_{2}$ directly out of the atmosphere, such as by using air scrubbers or growing large phytoplankton blooms in the oceans in order to absorb atmospheric $\mathrm{CO}_{2}$ (Shepherd 2009, 9-23). Once captured, the $\mathrm{CO}_{2}$ could be sequestered underground or in the deep ocean. If it works as planned, this would cancel the warming effect the sequestered $\mathrm{CO}_{2}$ otherwise would have had in the atmosphere. However, the costs of some forms of $\mathrm{CO}_{2}$ removal are currently projected to be quite high (Shepherd 2009, table 5.1). Further, the effectiveness of some forms of $\mathrm{CO}_{2}$ removal, such as fertilizing the oceans with iron in order to foster the growth of phytoplankton, is itself questionable (Strong et al. 2009).

A second category of geoengineering is solar radiation management, which would alter the quantity of solar radiation that is absorbed by the Earth's surface. In the context of climate change, SRM could be utilized to induce global cooling, thus counter-balancing the warming effect of atmospheric greenhouse gases. If it works, this form of geoengineering could avoid some of the potentially harmful impacts of climate change, such as sea-level rise caused by melting ice sheets (MacCracken 2009). Possible solar radiation management techniques include installing orbital space mirrors to reduce the quantity of radiation entering Earth’s atmosphere (Keith 2001) and marine cloud brightening to increase cloud albedo and reflect some solar radiation back into space (Jones, Haywood, and Boucher 2011). For the remainder of this paper, I will focus on what is perhaps the most often-discussed geoengineering technique in the scientific literature, namely AG, which would inject sulfate precursor (e.g., $\mathrm{SO}_{2}$ ) particles into the stratosphere, thus increasing the Earth's albedo and reducing the quantity of solar radiation reaching the Earth's surface. This would simulate the effects of a volcanic eruption (Brewer 
2007), reflecting some incoming sunlight back into space and thus providing a kind of sun shade that leads to global cooling. Since the degree of cooling can be altered depending on the quantity of aerosols injected into the stratosphere (Irvine, Ridgwell, and Lunt 2010), AG could be used as a global thermostat, turning down the temperature to counter-balance the global warming caused by increased concentrations of atmospheric greenhouse gases, potentially avoiding some (but not all) of the potentially harmful impacts of climate change.

\section{Advantages and Disadvantages of Aerosol Geoengineering.}

Aerosol geoengineering is expected to have certain advantages over other responses to climate change. Authors who have urged further research on AG have noted that it appears to be fast (Keith, Parson, and Morgan 2010), inexpensive (Barrett 2008), and capable of averting or diminishing some of the harmful impacts of climate change (MacCracken 2009). First, sulfate precursor aerosols seem to have a rapid impact on global temperatures, providing a significant cooling effect shortly after being injected into the stratosphere (Robock, Oman, and Stenchikov 2008). AG would be much faster than emissions mitigation, for example, since reducing or even eliminating emissions would not have an immediate, substantial effect on global temperatures. Given the long atmospheric lifetime of $\mathrm{CO}_{2}$ of centuries to millennia (Archer and Brovkin 2008), past emissions would continue to contribute to climate change. ${ }^{2}$ Second, AG is expected to be relatively inexpensive, costing much less than emissions mitigation (Barrett 2008; Teller et al. 2003). Further, AG could also be much less expensive than adaptation, depending on the severity of the impacts to which humans would need to adapt (IPCC 2007a). ${ }^{3}$ Third, if it works, AG could be used to avert or reduce certain potentially harmful impacts of climate change, such as 
sea-level rise that threatens persons living in coastal regions (MacCracken 2009) or reductions in agricultural productivity (Morgan and Ricke 2011, 13).

Yet proponents of further research also recognize that AG is “imperfect” (Keith, Parson, and Morgan 2010, 426). I examine four disadvantages of AG, namely that it would not address ocean acidification, that it could alter regional precipitation patterns, that it is subject to abrupt discontinuation, and that it is prone to unilateral deployment. ${ }^{4}$ Each of these disadvantages makes AG potentially harmful to some persons. Accordingly, the prospect of AG deployment raises significant ethical concerns (Gardiner 2010; Jamieson 1996; Svoboda et al. 2011). I consider each of these four disadvantages in turn.

First, increased ocean acidification is caused by elevated concentrations of atmospheric $\mathrm{CO}_{2}$. As more $\mathrm{CO}_{2}$ is emitted into the atmosphere, more is absorbed by the oceans, thus reducing ocean pH (Doney 2006; Doney et al. 2009). This change in ocean chemistry could interfere with the ability of some marine organisms (e.g., corals) to form shells of calcium carbonate, which in turn could have a deleterious impact of coral reef ecosystems (Hoegh-Guldberg et al. 2007). Unfortunately, AG would not address this problem, because it only compensates for global warming by initiating some degree of global cooling. AG would not slow or reverse the increasing concentrations of atmospheric $\mathrm{CO}_{2}$ that are driving ocean acidification.

Second, climate model simulations suggest that deploying AG could alter precipitation patterns, significantly reducing average annual precipitation in some regions (Matthews and Caldeira 2007). For example, AG could disrupt the Asian and African summer monsoons (Robock, Oman, and Stenchikov 2008) and potentially lead to droughts (Trenberth and Dai 2007). Precipitation change could also reduce agricultural productivity (although cf. Pongratz et al. 2012) and access to freshwater in some regions (Robock, Oman, and Stenchikov 2008). The 
degree to which AG impacts precipitation might depend on the quantity of aerosols that is injected into the stratosphere, with higher quantities tending to contribute to greater disruptions in precipitation (Irvine, Ridgwell, and Lunt 2010).

Third, once AG is deployed, there is a risk that it could be abruptly discontinued, leading to rapid climate change as aerosols dissipate (Goes, Keller, and Tuana 2011; Ross and Matthews 2009). Since sulfate aerosols have an atmospheric lifetime of only a few years (Rasch, Crutzen, and Coleman 2008), new stratospheric injections must be continually administered in order to maintain a constant concentration of aerosols and hence a stable cooling effect. If this maintenance should fail (e.g., due to war, terrorism, or technological malfunctions), the aerosols already in the stratosphere would disperse within several years, allowing global temperatures to increase rapidly (Goes, Keller, and Tuana 2011).

Fourth, given that AG is relatively inexpensive and does not require international agreement in order to be implemented, a single state could deploy AG unilaterally (Victor 2008; Victor et al. 2009). Unlike effective mitigation, which requires that various agents cooperate in cutting their emissions, AG could be deployed by one state over the objections of other states. Since different regions could be affected in different ways by AG (Irvine, Ridgwell, and Lunt 2010; Robock, Oman, and Stenchikov 2008), unilateral deployment by one state could be contrary to the interests of others, thus creating the potential for geopolitical conflicts (Victor et al. 2009). It is unclear how likely it would be that a single state would decide to deploy AG unilaterally, however. While Horton (2011) argues that states would have incentives to cooperate in deployment, Barrett (2008) notes that states especially vulnerable to climate change could have an interest in rejecting cooperation in favor of unilateralism. For the purposes of this paper, I only note that unilateral deployment of AG is a potential scenario. 


\section{The Ethics of Aerosols Geoengineering.}

The four disadvantages of AG discussed above have ethical significance. One reason for this is that ocean acidification, precipitation change, abrupt discontinuation, or unilateral deployment could result in substantial harm to persons, thus raising questions about whether that harm is ethically permissible. For example, ocean acidification could harm persons who depend on coral reef ecosystems for coastal protection or economic income from tourism (HoeghGuldberg et al. 2007), precipitation change could harm persons who experience drought or famine in affected regions (Robock, Oman, and Stenchikov 2008), discontinuous AG could harm future generations through rapid climate change (Goes, Keller, and Tuana 2011; Svoboda et al. 2011), and unilateral AG could harm persons in states that do not consent to AG deployment (Victor et al. 2009). Clearly, AG requires ethical evaluation.

Svoboda et al. (2011) argue that AG faces serious challenges to satisfying the requirements of most if not all theories of justice, including both egalitarian and desert-based theories (Rawls 1999; Dworkin 1981, 1981; Sen 1982; Arneson 1989; Olsaretti 2007). Specifically, we contend (1) that AG-induced precipitation change could harm some persons much more than others, potentially leading to a distributively unjust outcome; ${ }^{5}$ (2) that deploying AG could burden future generations with the risk of discontinuous AG, thus potentially violating intergenerational justice; and (3) that unilateral deployment of AG would exclude various persons affected by AG from contributing to the decision process concerning whether it should be deployed, thus potentially violating procedural justice. While this analysis raises ethical concerns regarding the potential deployment of AG, it does not necessarily imply that AG ought not to be deployed. The mere fact that some climate change strategy threatens to harm some 
persons, even in potentially unjust ways, does not automatically entail that this strategy ought not to be adopted. In order to determine whether a potentially harmful strategy ought to be adopted, further arguments should be considered. I will now examine four such arguments. The first three conclude that AG ought not to be deployed, whereas the fourth concludes that we ought to adopt the climate change strategy that would result in the least net harm to persons.

\section{Risks of Harm Due to Aerosol Geoengineering (Argument 1).}

If, contrary to my claim, it was the case that AG ought not to be deployed simply because it threatens to harm persons, something like the following argument (call it A1) would need to be sound:

P1: If we deploy AG, it could result in harm to some persons.

P2: We ought not to do anything that could result in harm to some persons.

C1: Therefore we ought not to deploy AG.

This argument is unsound because P2 is false. We are warranted in taking P2 to be false because it has very implausible implications. Since virtually all actions carry some risk of harm (i.e., they could result in harm to persons), P2 proscribes virtually all actions. It is instructive to try searching for examples of actions that do not carry risks of harming someone, whether oneself or another. By driving a car one risks striking a pedestrian; going outdoors carries a risk of developing skin cancer due to exposure to ultraviolent radiation, even if one takes precautions; a doctor performing surgery risks injuring or killing her patient; and so on. Most of us often find these risks negligible and worth taking, but this suggests that we really do not accept P2. If one 
was to adopt P2 as a principle, it frequently would counsel inaction regarding even very low-risk activities. ${ }^{6}$ I assume that this is an unacceptable implication. Accordingly, we should reject P2 and hence A1 as well.

\section{Harm Resulting from Aerosol Geoengineering (Argument 2).}

One might revise A1 in order to avoid this objection. Consider the following argument (call it A2):

P3: If we deployed AG, it would result in harm to some persons.

P4: We ought not to do anything that would result in harm to some persons.

C1: Therefore we ought not to deploy AG.

Unlike A1, this argument does not claim that AG merely threatens harm to persons (i.e., that it could harm them) but rather that, if deployed, it would in fact result in harm to persons. Hence, A2 is not prone to the objection that it implausibly proscribes any action or policy that merely carries some risk of harm. Moreover, P3 seems true-it is virtually certain that some person or persons would be harmed by an AG strategy, whether due to ocean acidification, precipitation change, abrupt discontinuation, unilateralism, or some other impact. Hence, whether A2 is sound hinges on the truth or falsity of P4.

Accepting P4 has very implausible implications. There are situations in which, as a matter of common sense, one is permitted to cause harm to a person, whether oneself or another. Examples might include self-defense against a malicious assailant or administering chemotherapy to a cancer patient. Each of these examples involves causing harm to some person, 
but it would be implausible to hold that a victim of attack is not permitted to defend himself against his assailant or that an oncologist is not permitted to administer chemotherapy (which certainly causes the patient to be harmed, even if it leads to eventual benefits) to her patient. If one holds that causing harm is justified in cases like these, then by consistency one should not accept P4, since the principle contained in that premise proscribes performing any action that would result in harm to persons.

Further, it is possible that there are scenarios in which all available courses of action would result in harm to persons. In such cases, complying with P4 would require one to reject all available courses of action, even if one of those courses of action was much less harmful than inaction. Yet this seems irresponsible. In a situation in which one has the option of either performing some slightly harmful action or allowing substantial harm to accrue by doing nothing, it seems that one ought to perform the slightly harmful action. Consider Peter Singer's well-known example of a person who encounters a drowning child in a shallow pond (Singer 1972, 231). If one does nothing, the child will die, which would be substantially harmful to the child as well as his family and friends. Yet if one dives into the water to save the child, the rescuer's shoes will be soiled, which (we may assume) would be slightly harmful to the rescuer. No one seriously accepts the view that one should not attempt to rescue the drowning child because it would ruin one's shoes, yet this is the course of action that would be prescribed by P4 in this situation. If one ought not to do anything that would result in harm to some persons, and attempting to rescue the child would harm a person (namely oneself), then one ought not to attempt to rescue the child. But this conclusion is untenable, which suggests that P4 should not be accepted. 
Arguably, climate change provides a scenario in which all available courses of action would result in harm for some persons. The available strategies include emissions mitigation, adaptation, geoengineering, or some hybrid of these (Wigley 2006). Emissions mitigation cannot prevent the harmful impacts resulting from the climate change to which we are already committed due to past emissions (Wetherald 2001), and realistic mitigation targets might not be sufficient to avoid additional harmful impacts from future emissions (Solomon et al. 2009). ${ }^{7}$ Adaptation measures could be insufficient to avoid all harm due to impacts from climate change, such as harm to persons living in small island developing states, whose territories could disappear due to sea-level rise (Byravan and Rajan 2010). As far as I am aware, all geoengineering techniques would probably result in harm for some persons, not only AG (Robock 2008). Finally, it is doubtful that a hybrid strategy can be found that would not harm some persons. For example, combining mitigation with AG (Wigley 2006), although it might reduce the harm that would result from either strategy on its own, probably would still harm some persons, e.g. through precipitation change. Thus, it is arguably the case that all available responses to climate change would result in harm to persons, although some could be substantially less harmful than others. If it is the case that all available climate change strategies would result in harm to persons, and if one accepts P4, then by consistency one should hold that none of these strategies should be adopted and that we ought instead to do nothing about climate change. If this seems implausible, then we should reject P4 and hence A2 as well.

\section{The Relative Harmfulness of Different Strategies (Argument 3).}

Taking account of this difficulty with A2, one might put forward the following argument instead (call it A3): 
P5: If we deployed AG as a climate change strategy, it would result in more harm to persons than some other available climate change strategy.

P6: We ought not to adopt any climate change strategy that would result in more harm to persons than some other available strategy.

C2: Therefore we ought not to deploy AG as a climate change strategy.

This argument relies on an ethical principle (P6) that is specific to climate change, which arguably allows us to avoid the problems associated with A2. ${ }^{8}$ First, unlike P4, P6 does not proscribe all harmful actions but instead holds that a climate change strategy should not be adopted if some other available strategy is less harmful. This is more plausible than P4, because accepting P6 is compatible with adopting a climate change strategy that causes harm to persons, provided that such a strategy results in less harm than all other available strategies. Accordingly, if all available climate change strategies would result in harm to persons, those who accept P6 need not reject all those strategies in favor of inaction.

Yet it is not clear whether P5 is true. As discussed above, mitigation strategies also could result in substantial harm to persons, given both that mitigation cannot reduce committed climate change and that realistic emissions cuts might be insufficient to avoid additional harmful impacts. Likewise, adaptation strategies could result in harm to persons as well, given that the more severe impacts of climate change might outstrip realistic adaptation measures. Whether the harm resulting from mitigation or adaptation strategies would be greater or less than the harm resulting from AG (or some other geoengineering strategy) is uncertain. Hence, it is unclear whether P5 is true. 
Further, P5 might be true at a certain point in time yet false at another, given that it is a contingent matter of fact whether or not AG would be more harmful than other climate change strategies. For example, it is possible that an aggressive mitigation strategy implemented within the next five years (say) would result in substantially less harm than an AG strategy deployed within the next five years. If so, then P5 would be true at present. But imagine that an aggressive mitigation strategy is not adopted in the near future and that rates of greenhouse gas emissions continue to accelerate. In this unfortunately plausible scenario (Solomon et al. 2009), it might become the case that in the future a mitigation strategy would result in more harm than an AG strategy. Given that AG can quickly reduce global temperatures (Keith, Parson, and Morgan 2010), and given that mitigation cannot reduce committed climate change due to past emissions, P5 could become false in the relatively near future even if it is true now. Accordingly, in evaluating A3, one would need to know when and under what conditions AG is being deployed in order to decide whether it is more or less harmful than other available climate change strategies.

Finally, it is controversial whether the principle contained in P6 should be accepted, because it implies that we ought to adopt a climate change strategy only if it would result in less total harm than any other available strategy. A rival principle is that we ought to adopt a climate change strategy only if it is on balance most beneficial, or if it results in the greatest net benefit. This is a rival principle because adopting the strategy that results in the greatest net benefit could entail rejecting the strategy that results in the least (total) harm, since that latter strategy might not deliver the greatest net benefit. Imagine a scenario in which climate change strategy A results in substantial total harm but even greater total benefit, such that it delivers a net benefit, whereas strategy B results in significantly less total harm but only miniscule total benefit, such that it 
produces no net benefit. ${ }^{9}$ In such a case, both the resultant total harm and the net benefit of $\mathrm{A}$ is greater than the resultant total harm and the net benefit of B. If one accepts P6, then by consistency one may not advocate strategy A over strategy B. Some will find this implausible. If one is sympathetic to classic utilitarianism (Mill 2008 [1861]), for example, then it might seem that one ought to adopt strategy A, since on balance it is more beneficial than strategy B (e.g., because it maximizes happiness). Of course, one need not be a classic utilitarian or even a consequentialist in order to think that one ought to adopt strategies that are on balance more beneficial than their competitors. For example, Kantians could hold that A ought to be adopted because it is required by a duty to promote the happiness of others (Kant 1996 [1797], 6:452-4). Conversely, negative utilitarians, who accept the ethical principle that one ought to minimize harms rather than maximize benefits (Popper 2002), might prefer strategy B to strategy A. However, negative utilitarianism has certain implausible implications (Smart 1958), such as that a world with neither harms nor benefits is preferable to a world with minor harms and great benefits. It is not my purpose here to determine whether the principle contained in P6 is true but only to note that it is controversial, thus making A3 controversial as well.

\section{Adopting the Strategy Resulting in the Least Net Harm (Argument 4).}

There is a way to avoid this controversy. Consider the following argument (call it A4):

P7: If every available climate change strategy would result in net harm to persons, then we ought to adopt that strategy that would result in the least net harm to persons. P8: Every available climate change strategy would result in net harm to persons. 
C3: Therefore we ought to adopt that response to climate change that would result in the least net harm to persons.

Given P7, this argument covers only cases in which all available climate change strategies are on balance harmful. In such a situation, so the argument goes, we ought to adopt that available strategy that would result in the least net harm to persons. Hence, the proponent of A4 can avoid the controversial commitments of the proponent of A3, given that the former holds only that if all available strategies are on balance harmful, then we should adopt that strategy that would result in the least net harm. Note also that a principle directing one to adopt that strategy resulting in the greatest net benefit would be of no use in such a situation, since no such strategy would be available.

As an ethical principle, P7 appears to be more plausible than P2, P4, or P6. Intuitively, it seems reasonable that, given an unfortunate choice among several courses of action that all result in net harm , one should adopt that course of action that is on balance least harmful. At the very least, it would seem that one has a very strong, pro tanto ethical reason to adopt the least harmful (on balance) course of action in such situations. Whether one has an all-things-considered ethical reason to do so is perhaps less clear, although some consequentialists might have no quarrel with accepting this. Others, however, might object that the net harm of actions is not the only ethically relevant factor to consider. For example, one might hold that considerations of distributive justice also matter in determining what climate change strategy ought to be adopted (Svoboda et al. 2011). Imagine that our choice is restricted to two climate change strategies, $C$ and $D$, both of which result in net harm to persons. Suppose that strategy $\mathrm{C}$ results in slightly more net harm than strategy $\mathrm{D}$, but that the harm resulting from $\mathrm{C}$ is distributed justly among persons whereas 
the harm resulting from D is distributed unjustly among persons. Depending on one's commitments in ethical theory, one might hold that strategy $\mathrm{C}$ ought to be adopted instead of strategy D. For someone who holds this, even in a scenario in which all available climate change strategies would result in net harm, the fact that some particular strategy would result in less net harm than any other does not yield an all-things-considered ethical reason to adopt that strategy, given that the least harmful strategy might result in a distributively unjust outcome. ${ }^{10}$ On this view, P7 would not be true as stated, because the fact that every available climate change strategy would result in net harm to persons would not be a sufficient condition for it to be the case that we ought to adopt that strategy that would result in the least net harm to persons.

Given the possibility of such a view, I will not here defend the claim that, in situations in which all available climate change strategies would result in net harm, one has an all-thingsconsidered ethical reason to adopt the strategy that would result in the least net harm. Instead, I suggest that, in such situations, one has at least a very strong, pro tanto ethical reason to adopt the least harmful strategy. Moreover, even those who deny that P7 is true could treat the principle stated in P7 as what Christine Korsgaard calls a "provisionally universal principle.” Unlike an “absolutely universal principle,” which holds without exception, a provisionally universal principle "applies to every case of a certain sort, unless there is some good reason why not” (Korsgaard 2009, 73). By treating P7 as a provisionally universal principle, one can recognize that it gives one not only a pro tanto ethical reason to adopt the strategy that would result in the least net harm, but also that, all else of ethical relevance being equal among available strategies, one ought to adopt that strategy. Further, given that the principle is provisionally universal, one can also recognize that there might be competing ethical reasons that could override this principle. For example, if it is not the case that all else of ethical relevance is 
equal among available strategies (e.g., because the strategy resulting in the least net harm also would result in a distributively unjust outcome, whereas other strategies would not), then there might be a good reason why the principle does not apply in that case. In such a situation, concerns about distributive justice might give one an ethical reason to adopt a strategy that does not result in the least net harm. I do not take a position in this paper on whether that is the case. However, even if this is true, the principle contained in P7, understood as provisionally universal, nonetheless offers a plausible guide: if every available climate change strategy would result in net harm to persons, then we ought to adopt that strategy which would result in the least net harm to persons, unless there is a sufficiently good ethical reason why we ought not to do so. ${ }^{11}$

One might counter that similar pro tanto provisions could be used to salvage the ethical principles critiqued in A1-3. For example, while it might be implausible to treat P2 (i.e., that we ought not to do anything that could result in harm to some persons) as an absolutely universal principle, it might be perfectly reasonable to hold that we have a pro tanto ethical reason not to do anything that could result in harm to some persons, although that reason could be over-ridden by competing considerations. This version of the principle in P2 would not be prone to the objection raised above, namely that it would proscribe virtually all actions. Similar pro tanto conditions could be attached to the principles in P4 and P6, likewise immunizing them from the corresponding objections discussed above. In that case, one might ask, why should we prefer a pro tanto version of the principle in $\mathrm{P} 7$ to a pro tanto version of one of these other principles?

Two different replies seem appropriate here. First, I have left it an open question whether the principle in P7 provides a pro tanto ethical reason or an all-things-considered ethical reason. If it is the latter, as some consequentialists might hold, then the question of why we should prefer 
a pro tanto $\mathrm{P} 7$ to a pro tanto $\mathrm{P} 2, \mathrm{P} 4$, or P6 does not arise. Second, even on a pro tanto interpretation, a major advantage of P7 over the other principles is that it would seem to provide superior action-guidance in relevant cases, such as climate emergencies. While it might be the case that we have pro tanto ethical reasons not to do anything that risks harm (P2) or results in harm (P4), these reasons are presumably over-ridden with regularity, since virtually any action risks harm and many harmful actions seem ethically permissible (e.g., providing chemotherapy to a patient). In particular, appealing to pro tanto versions of P2 and P4 would not be very helpful in deciding among competing climate change strategies, given that all of them are virtually certain both to risk harm and result in harm to some persons. For the purposes of choosing a climate change strategy, P2 and P4 arguably do not provide any action-guidance at all, since they merely counsel that we have pro tanto reasons not to choose any of the available options, thus giving no reason to prefer some strategies over others.

A pro tanto version of P6 fares somewhat better here, as it specific to the issue of climate change and takes into account the possibility that different strategies could be harmful to varying degrees. However, a pro tanto version of P7 seems more helpful still, because it provides superior action-guidance in climate emergency scenarios. In cases in which all available climate strategies would result in net harm to persons, we would want to know what we have good ethical reason to do, not merely what we have good ethical reasons not to do. Even in their pro tanto permutations, P2, P4, and P6 all hold that we have reason not to perform some kind of action, remaining silent on what we should do instead. Conversely, a pro tanto version of P7 holds that, in such cases, we have an ethical reason to adopt that climate change strategy that would result in the least net harm to persons. Thus, P7 seems more helpfully action-guiding than these other principles. 
Perhaps the more controversial claim in A4 is P8, which holds that all available climate change strategies would result in net harm to persons. This premise is uncertain and, like P5 above, might be true at some points in time yet false at others. One might argue that P8 is false at present, perhaps because mitigation or adaptation strategies could still secure outcomes that are on balance beneficial to persons. Yet it is not difficult to envision realistic, relatively near-future scenarios in which P8 is true. Such cases are not merely far-fetched intuition pumps. If highemitting states continue to make little headway in cutting greenhouse gas emissions during (say) the next few decades, then we can reasonably expect to commit ourselves to dangerous climate change in the future (IPCC 2007b, 8, 14), including elevated risks of threshold events or "tipping points” in the climate. Possible threshold events include melting permafrost causing the release of vast quantities of methane that in turn lead to increased global warming through a positive feedback loop (Heimann and Reichstein 2008), the shutdown of the oceans’ meridonal overturning circulation (Keller, Bolker, and Bradford 2004), or the collapse of polar ice sheets (MacCracken 2009). In such a scenario, it is plausible to expect that all available courses of action would be on balance harmful. First, doing nothing in such a situation is likely to result in net harm, due to the severe harms associated with ocean acidification, severe weather events, sea-level rise, and possible threshold events (IPCC 2007b). Second, given inertia in the climate system, emissions mitigation would be unable to avert or reduce those harmful impacts to which we are already committed due to past emissions (Solomon et al. 2009; Wetherald 2001). If these committed impacts are on balance harmful, as seems plausible given the severe harms just mentioned, then a mitigation strategy likewise would result in net harm. ${ }^{12}$ Third, there are limits to how much harm could be averted via adaptation techniques, especially in the case of high impact threshold events, such as a shutdown of the meridonal overturning circulation in the 
Earth’s oceans (Keller, Bolker, and Bradford 2004). Moreover, adaptation strategies are likely to carry substantial costs (IPCC 2007a, 13) and significant hardships of their own, such as in the case of climate migrants fleeing the effects of rising sea levels (Byravan and Rajan 2010). In a future scenario in which we are committed to dangerous climate change and in which there are elevated risks of threshold events, it is not outlandish to expect that adaptation strategies would be insufficient to avoid net harm. Finally, given the various disadvantages of geoengineering (e.g., that AG would not address all harmful impacts of climate change and that it carries substantial risks of its own), we may reasonably assume that adopting a geoengineering strategy in such a future scenario would likewise result in net harm. Arguably then, if emissions are not substantially reduced soon, P8 might become true in the future, even if it is false at present. While this cannot be predicted with certainty, it seems plausible to believe that, given the lack of serious progress on mitigating emissions, we are on course for such a scenario.

\section{Which Strategy Would Result in the Least Net Harm?}

I have suggested that the principle contained in P7 is a more helpful guide to considering the ethics of AG than any of the principles contained in A1-3. This is because the principle in P7, whether it is conceived as an absolutely or provisionally universal principle, is both more plausible than those in P2, P4, and P6 and is more helpfully action-guiding than those other principles. Moreover, many of those who propose further research on AG argue that it could be an attractive strategy in climate emergency scenarios, such as those involving certain threshold events in the climate (Crutzen 2006; Keith, Parson, and Morgan 2010). As argued above, it is plausible to think that such scenarios would be situations in which all available climate change strategies would on balance be harmful, such as by causing substantial harm to some while 
delivering little or no benefit for others. Moreover, it might be the case that neither mitigation nor adaptation strategies would be able to avoid this net harm, for the reasons discussed above. Especially if a threshold collapse is imminent, it could be too late either for mitigation efforts to avert a tipping point or for adaptation measures adequately to prepare for it.

In such a scenario, it makes sense to examine which available climate change strategy would best minimize the net harm. There is some prima facie evidence that AG could be (or be part of) that strategy in such situations. Given that it has a fast cooling effect (Keith, Parson, and Morgan 2010), AG might be able to avert otherwise-imminent threshold collapses before they occur, thus avoiding the harm that otherwise would result from such events. ${ }^{13}$ For example, by rapidly cooling the Earth, AG might be able to halt the release of large quantities of methane from melting Arctic tundra (Morgan and Ricke 2011, 14), avert an impending collapse of polar ice sheets (MacCracken 2009; Irvine et al. 2009), or avoid a shutdown of the meridonal overturning circulation (Crutzen 2006, 241; MacCracken 2006). Even if AG would result in net harm to persons, this might be substantially less than the net harm that would result from allowing these threshold collapses to occur. Moreover, in such an emergency scenario, the resulting net harm of AG might also be less than that resulting from mitigation, adaptation, or other geoengineering strategies, since non-AG strategies are unlikely to avoid or diminish the impacts of an imminent threshold collapse. Hence, in such a scenario, AG could be on balance less harmful than all other available strategies. If the principle in P7 is an absolutely universal principle, then AG ought to be deployed in that scenario. However, even if the principle in P7 is only a provisionally universal principle, it still provides a powerful, pro tanto ethical reason to deploy AG in such a scenario, although there might be countervailing ethical reasons why AG 
ought not be deployed. In that case, the weight of these competing ethical reasons would need to be considered in order to decide what ought to be done.

\section{Further Research.}

Much work remains to be done on AG. Further research is needed to reduce uncertainty about the potential impacts of AG, perhaps revealing that AG would be significantly more or less harmful than currently thought. More research also could help to devise ways in which the harm resulting from AG could be reduced. Examples might include coupling AG with emissions mitigation (Wigley 2006), compensating those who are harmed by AG deployment (Bunzl 2011), and/or establishing an international treaty to reduce the risk of unilateral AG (Victor 2008). ${ }^{14}$ Further research also is needed to address questions concerning both the permissibility of AG deployment, as I have attempted to do here, and the ethics of researching AG (Morrow, Kopp, and Oppenheimer 2009). For example, field tests of AG would involve stratospheric aerosol injections and hence carry their own risks of harm, thus raising questions of what conditions must be met in order for field tests to be permissible, whether victims of such tests would be compensated, how research decisions ought to be made, and so on (Tuana et al. 2011). Moreover, Gardiner (2010) raises a number of worries about what he calls the "Arm the Future Argument," according to which substantial research on AG should proceed soon, both because there is a high probability of a climate emergency scenario in the future and because AG deployment would be the least bad option in such a scenario. Gardiner claims that this argument does not by itself provide a definitive case for conducting AG research because it overlooks important issues, such as that AG research could pose a moral hazard, that there could be nongeoengineering options for dealing with an emergency scenario, and that political inertia could 
lead to unjust uses of AG if it is researched, among others (Gardiner 2010, 291-295). ${ }^{15}$ In this paper, I have not addressed ethical questions regarding research on AG, but such questions are obviously important and require careful consideration.

\section{Closing Comments.}

I have not argued in this paper that AG ought to be deployed. Instead, I have argued for a conditional claim: if we were in a situation in which all available climate change strategies were on balance harmful, and if AG was (or was part of) the strategy that would be on balance least harmful, then we have at least a powerful, pro tanto ethical reason to deploy AG. ${ }^{16}$ Moreover, I have suggested that certain climate emergency scenarios, particularly those involving threshold collapses, are plausibly taken to be situations in which both these conditions are satisfied, although this would need to be determined in each particular case. Finally, I have proposed that such emergency scenarios are not merely far-fetched possibilities. Given current emissions trajectories, it is not implausible to expect both a future scenario in which all available climate change strategies would result in net harm and that AG would be (or be part of) the strategy resulting in the least net harm. The upshot of all this is that, despite the risks of substantial harm associated with AG, it is not clearly the case that AG ought not to be deployed. On the contrary, there are plausible cases in which AG is ethically preferable to available alternatives.

\section{Acknowledgments.}

Earlier versions of this paper were presented at the $17^{\text {th }}$ International Conference of the Society for Philosophy and Technology (University of North Texas, May 2011), the poster session of the $4^{\text {th }}$ annual Rocky Mountain Ethics Congress (University of Colorado, August 2011), the NSF- 
sponsored Climate Ethics Works-in-Progress Conference (University of Alaska Anchorage, September 2011), and the 2012 American Philosophies Forum Symposium (Pennsylvania State University, April 2012). I would like to thank participants of these conferences for very helpful feedback and discussion. I would also like to thank David Agler, Peter J. Irvine, Ryan Pollock, Kate Woodford, and an anonymous reviewer for insightful comments on drafts of this paper.

\footnotetext{
${ }^{1}$ Throughout this paper, I focus on harm to persons rather than harm to non-persons. This is because (1) I lack space to consider harm to non-human animals, flora, or ecosystems, and (2) there has been little scientific research on the impacts AG could have on non-humans, thus making it difficult to comment on such potential harm.
}

${ }^{2}$ Moreover, given that the atmospheric lifetime of sulfate precursor aerosols is measured in years rather than centuries or millennia (Robock 2000), the cooling effect of AG perhaps could be discontinued relatively quickly if it was found to have harmful impacts (Keith, Parson, and Morgan 2010), although it is unclear whether a rapid shutdown of AG could be performed safely (Irvine, Sriver, and Keller 2012).

${ }^{3}$ To take just one example, the Intergovernmental Panel on Climate Change (IPCC) warns, "Towards the end of the 21st century, projected sea-level rise will affect low-lying coastal areas with large populations [in Africa]. The cost of adaptation could amount to at least 5-10\% of Gross Domestic Product (GDP)” (IPCC 2007a, 13).

${ }^{4}$ Others disadvantages of AG include the potential for sulfate aerosols to cause ozone depletion (Tilmes, Müller, and Salawitch 2008) and the possibility that researching AG poses a moral hazard (Bunzl 2009).

${ }^{5}$ I add here that ocean acidification also poses a serious obstacle to AG meeting the requirements of distributive justice, as it could harm some persons much more than others.

${ }^{6} \mathrm{P} 2$ would seem to be entailed by certain strong versions of the precautionary principle. For discussion, see Gardiner (2006).

${ }^{7}$ Strictly speaking, some of these strategies would not cause persons to be harmed but would only allow them to be harmed. I lack space in this paper to consider whether there is a morally relevant distinction between doing and allowing (see Singer 1972; Scheffler 2004).

${ }^{8}$ Moreover, as I discuss later in this paper, ethical principles that are specific to climate change would seem to offer superior action-guidance when it comes to deciding what climate change strategy to adopt. 
${ }^{9} \mathrm{I}$ am not claiming that there is in fact some climate change strategy that both causes more harm than some other strategy and is on balance more beneficial than that other strategy. That is an open question.

${ }^{10}$ On way to address or at least ameliorate this potential problem is to compensate those victims of AG who receive a distributively unjust allocation of harms. One might argue, for example, that beneficiaries of AG have a responsibility to remunerate those who are harmed by AG. This could go some distance in at least reducing violations of distributive justice.

${ }^{11}$ Stated this way, the argument would need to be reformulated in order to maintain the same conclusion (call this A5):

P9: If every available climate change strategy would result in net harm to persons, then we ought to adopt that strategy that would result in the least net harm to persons, unless there is a sufficiently good ethical reason why we ought not to do so.

P10: It is not the case that there is a sufficiently good ethical reason why we ought not to adopt that strategy that would result in the least net harm to persons

P11: Therefore, if every available climate change strategy would result in net harm to persons, then we ought to adopt that strategy that would result in the least net harm to persons.

P12: Every available climate change strategy would result in net harm to persons.

C5: Therefore we ought to adopt that strategy that would result in the least net harm to persons.

I am not here endorsing this argument. P10 is controversial and I do not know whether it is (or, in certain scenarios, would be) true. Moreover, A4 might be sound, in which case the extra premises provided by A5 would be superfluous.

12 This is not to deny that we still would have ethical reasons to pursue emissions mitigation (e.g. for the sake of more distant future generations), perhaps as part of a hybrid mitigationgeoengineering strategy (Wigley 2006).

${ }^{13}$ It is currently an open question how well imminent threshold collapses could be predicted prior to their occurrence. Such events might not be recognized with sufficient time left to deploy geoengineering (Tuana et al. 2011). This could make it difficult to determine at a particular time whether P8 is true, thus raising application problems for the proponent of deploying AG in emergency scenarios.

${ }^{14}$ Such further research is highly unlikely to remove all uncertainty, of course. Nonetheless, it can reduce uncertainty about these various issues. This is surely a desirable goal, since it would allow us better to assess both the impacts of different strategies and their propensity to result in harm or benefit. 
${ }^{15}$ Initially, it might seem that Gardiner's critique also applies to my thesis in this paper, namely that it could be the case that AG ought to be deployed in climate emergency scenarios. However, Gardiner's major objection to the "Arm the Future Argument" is that it does not by itself provide a definitive basis to proceed with AG research. Even if this is true, the objection does not challenge my thesis that it could be the case that AG ought to be deployed in climate emergency scenarios.

${ }^{16}$ Some have asked whether, given uncertainty about climate change and the impacts of AG, it would be more appropriate to rely on an ethical principle that somehow countenances the risks associated with different strategies. While considerations of risk are important, I view them as distinct from identifying an appropriate ethical principle regarding whether or not AG ought to be deployed in certain scenarios. Due to uncertainty within some scenario, it might be unclear whether or not AG would result in less net harm than other strategies. In that case, deploying AG would risk resulting in more net harm than other strategies. This seems to be an epistemic issue, insofar as it could be very challenging in some scenarios to determine the relative harms and benefits of AG.

References.

Archer, D., and V. Brovkin. 2008. "The Millennial Atmospheric Lifetime of Anthropogenic

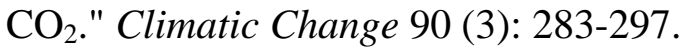

Arneson, Richard. 1989. "Equality and Equal Opportunity for Welfare." Philosophical Studies 56 (1): 77-93.

Barrett, Scott. 2008. "The Incredible Economics of Geoengineering." Environmental and Resource Economics 39 (1): 45-54.

Brewer, Peter G. 2007. "Evaluating a Technological Fix for Climate." Proceedings of the National Academy of Sciences 104 (24): 9915-9916.

Bunzl, Martin. 2009. "Researching Geoengineering: Should Not or Could Not?" Environmental Research Letters 4 (4).

Bunzl, Martin. 2011. "Geoengineering Harms and Compensation." Stanford Journal of Law, Science \& Policy 4: 70-76. 
Byravan, Sujatha, and Sudhir Chella Rajan. 2010. "The Ethical Implications of Sea-Level Rise Due to Climate Change." Ethics and International Affairs 24 (3): 239-260.

Crutzen, Paul J. 2006. "Albedo Enhancement by Stratospheric Sulfur Injections: A Contribution to Resolve a Policy Dilemma?" Climatic Change 77 (3-4): 211-219.

Doney, S. C. 2006. "The Dangers of Ocean Acidification." Scientific American 294 (3): 38-45.

Doney, Scott C., V. J. Fabry, R. A. Feely, and J. A. Kleypas. 2009. "Ocean Acidification: The Other $\mathrm{CO}_{2}$ Problem." Annual Review of Marine Science 1: 169-192.

Dworkin, Ronald. 1981. "What Is Equality? Part 1: Equality of Welfare." Philosophy and Public Affairs 10 (3): 185-246.

Dworkin, Ronald. 1981. "What Is Equality? Part 2: Equality of Resources." Philosophy and Public Affairs 10 (4): 283-345.

Gardiner, Stephen M. 2004. "Ethics and Global Climate Change." Ethics 114 (3): 555-600.

Gardiner, Stephen M. 2006. "A Core Precautionary Principle." Journal of Political Philosophy 14 (1): 33-60.

Gardiner, Stephen M. 2010. "Is 'Arming the Future' with Geoengineering Really the Lesser Evil? Some Doubts About the Ethics of Intentionally Manipulating the Climate System." In Climate Ethics, edited by Stephen Gardiner, Simon Caney, Dale Jamieson and Henry Shue. Oxford: Oxford University Press.

Goes, Marlos, Klaus Keller, and Nancy Tuana. 2011. "The Economics (or Lack Thereof) of Aerosol Geoengineering." Climatic Change 109 (3-4): 791-825.

Heimann, Martin, and Markus Reichstein. 2008. "Terrestrial Ecosystem Carbon Dynamics and Climate Feedbacks." Nature 451 (7176): 289-292. 
Hoegh-Guldberg, O., P. J. Mumby, A. J. Hooten, R. S. Steneck, P. Greenfield, E. Gomez, C. D. Harvell, P. F. Sale, A. J. Edwards, K. Caldeira, N. Knowlton, C. M. Eakin, R. IglesiasPrieto, N. Muthiga, R. H. Bradbury, A. Dubi, and M. E. Hatziolos. 2007. "Coral Reefs under Rapid Climate Change and Ocean Acidification." Science 318 (5857): 1737-1742. Horton, Joshua. 2011. "Geoengineering and the Myth of Unilateralism: Pressures and Prospects for International Cooperation." Stanford Journal of Law, Science \& Policy 4: 56-69. IPCC. 2007a. Climate Change 2007: Impacts, Adaptation and Vulnerability: Cambridge: Cambridge University Press.

IPCC. 2007b. Climate Change 2007: The Physical Science Basis. Cambridge: Cambridge University Press.

Irvine, Peter J., Daniel J. Lunt, Emma J. Stone, and Andy Ridgwell. 2009. "The Fate of the Greenland Ice Sheet in a Geoengineered, High $\mathrm{CO}_{2}$ World." Environmental Research Letters 4 (4).

Irvine, Peter J., Andy Ridgwell, and Daniel J. Lunt. 2010. "Assessing the Regional Disparities in Geoengineering Impacts." Geophysical Research Letters 37 (18).

Irvine, Peter J., Ryan L. Sriver, Klaus Keller. 2012. "Tension between Reducing Sea-Level Rise and Global Warming through Solar-Radiation Management." Nature Climate Change 2 (2): $97-100$.

Jamieson, Dale. 1996. "Ethics and Intentional Climate Change." Climatic Change 33 (3): 323336. 
Jones, Andy, Jim Haywood, and Olivier Boucher. 2011. "A Comparison of the Climate Impacts of Geoengineering by Stratospheric $\mathrm{SO}_{2}$ Injection and by Brightening of Marine Stratocumulus Cloud." Atmospheric Science Letters 12 (2): 176-183.

Kant, Immanuel. 1996 [1797]. The Metaphysics of Morals. In Immanuel Kant: Practical Philosophy, translated and edited by Mary J. Gregor. Cambridge: Cambridge University Press.

Keith, David. 2001. "Geoengineering the Climate: History and Prospect." Annual Review of Energy and the Environment 25: 245-284.

Keith, David W., Edward Parson, and M. Granger Morgan. 2010. "Research on Global Sun Block Needed Now." Nature 463 (7280): 426-427.

Keller, Klaus, Benjamin M. Bolker, and David F. Bradford. 2004. "Uncertain Climate Thresholds and Optimal Economic Growth." Journal of Environmental Economics and Management 48 (1): 723-741.

Korsgaard, Christine M. 2009. Self-Constitution: Agency, Identity, and Integrity: Oxford: Oxford University Press.

Lobell, David B., Marshall B. Burke, Claudia Tebaldi, Michael D. Mastrandrea, Walter P. Falcon, and Rosamond L. Naylor. 2008. "Prioritizing Climate Change Adaptation Needs for Food Security in 2030." Science 319 (5863): 607-610.

MacCracken, Michael C. 2006. "Geoengineering: Worthy of Cautious Evaluation?" Climatic Change 77 (3-4): 235-243.

MacCracken, Michael C. 2009. "On the Possible Use of Geoengineering to Moderate Specific Climate Change Impacts." Environmental Research Letters 4 (4). 
Matthews, H. Damon, and Ken Caldeira. 2007. "Transient Climate--Carbon Simulations of Planetary Geoengineering." Proceedings of the National Academy of Sciences 104 (24): 9949-9954.

Mill, John Stuart. 2008 [1861]. "Utilitarianism." In Utilitarianism and on Liberty, edited by M. Warnock. Oxford: Blackwell.

Morgan, M. G., and K. Ricke. 2011. Cooling the Earth through Solar Radiation Management: The Need for Research and an Approach to Its Governance Geneva: International Risk Governance Council.

Morrow, David R., R. E. Kopp, and M. Oppenheimer. 2009. "Toward Ethical Norms and Institutions for Climate Engineering Research." Environmental Research Letters 4 (4).

Nordhaus, W. D. 2001. "Global Warming Economics." Science 294 (5545): 1283-1284.

Olsaretti, Serena. 2007. Desert and Justice. Oxford: Oxford University Press.

Pongratz. J., D. B. Lobell, L. Cao, and K. Caldeira. "Crop Yields in a Geoengineered Climate." Nature Climate Change 2: 101-105.

Popper, Karl. 2002. The Open Society and Its Enemies: The Spell of Plato: Lond: Routledge.

Rasch, P. J., P. J. Crutzen, and D. B. Coleman. 2008. "Exploring the Geoengineering of Climate Using Stratospheric Sulfate Aerosols: The Role of Particle Size." Geophysical Research Letters 35.

Rawls, John. 1999. A Theory of Justice, revised edition. Cambridge: Harvard University Press.

Robock, A. 2000. "Volcanic Eruptions and Climate." Reviews of Geophysics 38 (2): 191-219.

Robock, A., L. Oman, and G. L. Stenchikov. 2008. "Regional Climate Responses to Geoengineering with Tropical $\mathrm{SO}_{2}$ Injections." Journal of Geophysical Research-Atmospheres 113. 
Robock, Alan. 2008. "20 Reasons Why Geoengineering May Be a Bad Idea." Bulletin of the Atomic Scientists 64 (2): 14-18.

Ross, Andrew, and H. Damon Matthews. 2009. "Climate Engineering and the Risk of Rapid Climate Change." Environmental Research Letters 4 (4).

Scheffler, Samuel. 2004. "Doing and Allowing." Ethics 114 (2): 215-239.

Sen, Amartya. 1982. "Equality of What?" In Choice, Welfare and Measurement, edited by A. Sen. Cambridge: Cambridge University Press.

Shepherd, John. 2009. Geoengineering the Climate: Science, Governance and Uncertainty. London: The Royal Society.

Singer, Peter. 1972. "Famine, Affluence, and Morality." Philosophy \& Public Affairs 1 (3): 229243.

Singer, Peter. 2004. One World: The Ethics of Globalization. New Haven: Yale University Press.

Smart, R. N. 1958. "Negative Utilitarianism." Mind 67 (268): 542-543.

Solomon, Susan, Gian-Kasper Plattner, Reto Knutti, and Pierre Friedlingstein. 2009.

"Irreversible Climate Change Due to Carbon Dioxide Emissions." Proceedings of the National Academy of Sciences 106 (6): 1704-1709.

Strong, Aaron, Sallie Chisholm, Charles Miller, and John Cullen. 2009. "Ocean Fertilization: Time to Move On." Nature 461 (7262): 347-348.

Svoboda, Toby, Klaus Keller, Marlos Goes, and Nancy Tuana. 2011. "Sulfate Aerosol Geoengineering: The Question of Justice." Public Affairs Quarterly 25 (3): 157-180.

Teller, E., R. Hyde, M. Ishikawa, J. Nuckolls, and L. Wood. 2003. "Active Stabilization of Climate: Inexpensive, Lowrisk, Near-Term Options for Preventing Global Warming and 
Ice Ages Via Technologically Varied Solar Radiative Forcing." Lawrence Livermore National Library.

Tilmes, Simone, R. Müller, and R. Salawitch. 2008. "The Sensitivity of Polar Ozone Depletion to Proposed Geoengineering Schemes." Science 320 (5880): 1201-1204.

Trenberth, Kevin E., and Aiguo Dai. 2007. "Effects of Mount Pinatubo Volcanic Eruption on the Hydrological Cycle as an Analog of Geoengineering." Geophysical Research Letters 34 (15).

Tuana, N., R. Sriver, T. Svoboda, R. Tonkonojenkov, P. Irvine, J. Haqq-Misra, and K. Keller. 2011. "Towards Integrated Ethical and Scientific Analysis of Geoengineering: A Research Agenda." Ethics, Policy \& Environment. In press.

Victor, D. G., M. G. Morgan, J. Apt, J. Steinbruner, and K. Ricke. 2009. "The Geoengineering Option." Foreign Affairs 88 (2): 64-76.

Victor, David G. 2008. "On the Regulation of Geoengineering." Oxford Review of Economic Policy 24 (2): 322-336.

Wetherald, R. T., Stouffer, R. J., Dixon, K. W. 2001. "Committed Warming and Its Implications for Climate Change." Geophysical Research Letters 28 (8): 1535-1538.

Wigley, T. M. L. 2006. "A Combined Mitigation/Geoengineering Approach to Climate Stabilization." Science 314 (5798): 452-454. 